\title{
SOBRE LA CONSTITUCIÓN DE LOS OBJETOS ETNOLÓGICOS EN LOS INICIOS DEL SIGLO XX: MUSEOS, FALSIFICACIONESY CIENCIA
}

\author{
Irina Podgorny ${ }^{* *}$
}

\section{RESUMEM:}

Este trabajo analiza algunos aspectos de las falsificaciones en relación al espacio de la colección y del museo y la conformación del saber etnológico de inicios del siglo $X X$. Primeramente, se dedica a la autoridad de los objetos como testimonio o evidencia y a la distinción entre las piezas verdaderas $y$ falsas en los museos en la época de delimitación de una "geografía de la autenticidad". La falsificación, puede afirmarse, genera un saber cruzado por las formas de la pericia policial, la crítica de los testimonios y las colecciones. Finalmente, nos referiremos a una controvertida "falsificación arqueológica" en los museos argentinos de la década de 1930.

\section{PALABRAS-CLAVES:}

Falsificaciones. Arqueología.Arroyo leyes. Siglo XX.

\begin{abstract}
:
This paper analyzes some aspects connected to archaeological and ethnological fakes incorporated into the museum collections. In that sense, it explores how the study and the controversies over fkes and falsehood shaped ethnological knowledge and the way of dealing with the materiality of the objects. The last part of the paper is devoted to a particular episode: the pottery found in the 1930s in Arroyo Leyes, Santa Fe, Argentina.
\end{abstract}

\section{KEY-WORDS:}

Fakes. Archaeology. Argentina. 19th Century.

I *Archivo Histórico y Fotográfico na Facultad de Ciencias Naturales y Museo da Universidad Nacional de la Plata/ Consejo Nacional de In-vestigaciones Científicas y Técnicas. 
En 1907, la Sociedad Etnológica de Berlín publicaba un corto informe de Richard Andrée (1835-1912) sobre su visita a los talleres de pulido de piedras semipreciosas de Idar-Oberstein (RICHARD, 1907, p. 943), entre los que se contaban los de la familia Wild, establecidos en 1840, cuyos miembros se habían perfeccionado como orfebres en Hannover y San Petersburgo. Desde 1850 el artesanado joyero de Idar-Oberstein se había expandido, comprando materias primas y vendiendo productos en distintas partes de mundo. Reemplazaron las piedras locales con otras llegadas del Brasil, el Índico y Australia y participaron en las exposiciones universales de Filadelfia (1876), Sydney (1879) y Melbourne ( 1880 , donde los Wild obtuvieron varios premios. Rápidamente la joyería de Idar, encontró buena comercialización en Europa y en América. Para 1907, cada rama de los Wild se había especializado en alguna materia prima exótica, como las perlas o el jade verde de Nueva Zelanda, objetos con los que incrementaron el comercio, a través de representantes en París, Birmingham y Glasgow.

Andrée se concentró en las réplicas en jade verde de armas, tikis, meres y otras piezas maoríes, vendidas en la calle principal de la ciudad. No se trataba de imitaciones secretas, muy por el contrario, el fabricante se exhibía orgulloso, así como su trabajo basado en modelos verdaderos. Para Richard (1907), editor de la popular revista Globus, la industria de Idar, más que una manifestación genuina de la historia del Siglo XIX, revelaba algo peculiar: si bien no había intenciones fraudulentas, estos objetos eran encargos ingleses que luego iban hacia Nueva Zelanda para ser vendidos como elementos de la "verdadera cultura maori". El comercio y el turismo, probablemente, los haría regresar a Alemania, donde se los podría volver a observar en las vitrinas de los museos etnográficos. El circuito era el siguiente: los Wild recibían los nódulos de jade a través de Inglaterra o Nueva Zelanda. De allí llegaban también los patrones, algunos en piedra, otros en madera. Para Richard (1907), las copias de Idar no se distinguían en nada de estos prototipos, por lo que resumía: el material es verdadero, las formas, exactamente como las originales, el pulido, igual de bello. ¿Qué valor tenían esos objetos para la etnología del siglo que se iniciaba?

El informe de Richard (1907) constituye un tópico de la literatura etnológica y arqueológica del cambio de siglo, expresando una preocupación nacional y denunciando los casos locales. En distintas ciudades del mundo, allí donde hubiera un museo, colecciones y sociedades eruditas o un corresponsal, se alertaba:"cuidado con incorporar imitaciones en las colecciones de nuestros museos” (BATRES, [19--?], EDGE-PARTINGTON, 1909; 1910; LEHMANN-NISTCHE, 1905; MUNRO, 1905; OLDMAN, 1910). Los manuales para distinguir lo verdadero de lo falso proliferaron al ritmo de la fabricación y el consumo de objetos exóticos en la ciudad moderna. Si bien los especialistas creían contar con más herramientas para distinguir lo genuino de lo apócrifo, todos, aficionados y profesionales, compartían la obsesión por "la cosa real y auténtica” (cf. GUMBRECHT, 1997; ORVELL, 1989), como sinónimo de un objeto representativo de una cultura congelada en un momento histórico, y la paradoja creada por ese mismo requisito. En efecto, cuanto más raro, el objeto adquiriría mayor valor científico y comercial, pero asimismo, llegaba a los límites de lo sospechoso. Así, el etnólogo alemán Graebner (1940, p. 25) diría: “La fantasía creadora opera más desenfrenadamente, como es natural, allí donde se trata de echar al mercado tipos completamente nuevos de regiones poco conocidas". Por otro lado, los objetos exóticos, una vez reconocidas sus técnicas de elaboración, podían ser sometidos al proceso de producción seriada. En ese proceso, como decía Richard (1907), forma, materia y técnicas eran verdaderas, pero el objeto resultante, una "copia," 
perdiendo valor como pieza de museo. Este trabajo analiza algunos aspectos de las falsificaciones en relación al espacio de la colección y del museo y la conformación del saber etnológico de inicios del siglo XX. Primeramente, se dedica a la autoridad de los objetos como testimonio o evidencia y a la distinción entre las piezas verdaderas y falsas en los museos en la época de delimitación de una "geografía de la autenticidad" (GUMBRECHT, I997). La falsificación, puede afirmarse, genera un saber cruzado por las formas de la pericia policial, la crítica de los testimonios y las colecciones. Finalmente, nos referiremos a una controvertida "falsificación arqueológica" en los museos argentinos de la década de 1930.

\section{La autoridad de las piedras en las humanas y divinas Letras}

A principios del Siglo $X X$ se trataría de hacer hablar a las piedras y objetos despojados de signos descifrables. Los objetos prehistóricos o etnológicos serían definidos por su "carácter inmediato": comprobada su autenticidad, podían constituirse en el testimonio directo de sí mismos, es decir

un seguro comprobante objetivo, cuando menos de la existencia del fenómeno cultural que representa en el lugar y tiempo que pertenece. Un interrogante puede solamente formularse respecto de si el objeto que pretende ser testimonio directo lo es o no lo es. En otras palabras: ¿el objeto, es auténtico o es una imitación, una falsificación? (GRAEBNER, 1940, p. 16).

Los hechos etnológicos de principio del Siglo XIX resultarían de un testimonio colocado en el mero objeto, índice de la existencia de otra cultura.A diferencia de las relaciones, donde "los hechos siempre han pasado a través de un espíritu humano, por lo menos” (GRAEBNER, 1940, p. I5), el objeto llegaba sin mediaciones, trayendo al museo el testimonio de la vida de los pueblos de otros espacios y tiempos. Si los "hechos" científicos resultan de ciertas convenciones (SHAPIN; SCHAFFER, I 985), la pregunta por la autenticidad de las cosas se tornaría el mecanismo para definir el "testimonio directo" del objeto etnológico del Siglo XX. Retomando una preocupación de los curadores de los museos y de los turistas del tardío siglo XIX, los etnólogos debieron cimentar su autoridad y erigirse en los únicos capacitados en ejercer la crítica de las fuentes. Por eso, la "falsificación" fue percibida como una amenaza a la misma credibilidad de esta disciplina que, a fines del siglo XIX, quería consolidar su carácter científico.

El problema de cómo distinguir las falsificaciones se había planteado antes en los círculos de la industria de alimentos y en relación a la circulación de la moneda. El fin de siglo XIX y los inicios del XX presencian la proliferación de manuales sobre falsificaciones referidas a los productos alimenticios, las bebidas alcohólicas, los remedios, el café, el té, el chocolate y las especias. Los análisis químicos y físicos de los componentes del producto "real” mostraban el camino a seguir. Estos manuales generales trataban también las falsificaciones de objetos de arte. Se trataban de iniciativas individuales, donde el Estado no intervenía y donde la solución del problema permanecía en el círculo de los damnificados. Por ello, a mitad del siglo XX, puede decirse: "lo más notable en la historia de las falsificaciones, que es poco menos que infinita, resulta el tiempo que hubo de transcurrir hasta que la policía les hiciera frente con todo el poder de que está dotada" (MENDAZ 1959, p. 19).

En 1932, A.Vayson de Pradenne, ingeniero de minas y antiguo presidente de la Société Préhistorique Française, presentaba los fraudes más notorios en el marco de la arqueología prehistórica, repitiendo una serie conocida por otros 
estudiosos (Mortillet, Munro y Eudel): “Flint Jack” en las islas británicas (I84I1862); las antigüedades lacustres de Concise (1859); la mandíbula de Moulin-Quignon (1863-64...); los huesos grabados de las grutas del Chaffaud (1863-5); el oso y el zorro de Thayngen (1873-7); la era del hueso en Pollina (I880-5); la edad del cuerno en Suiza (1882-7); los sílex de Breonio y el hacha de Cumarola, Italia (I88I-1906); la tiara de Saïtapharnès (I896-1903). Las noticias de estos fraudes circulaban internacionalmente a través de los periódicos: los diarios de La Plata publicaban crónicas de los tribunales de Friburgo sobre "un fraude que va a echar por tierra muchas teorías arqueológicas", refiriéndose al descubrimiento del hombre neolítico de la "edad del cuerno" de los palafitos de los lagos suizos. Estas noticias transmitían, además, la burla hacia los "harto crédulos sabios", autores de "ingeniosas verdades que corren como verdades de a puño por todos los libros de ciencia del mundo", subrayando que en lo futuro habría que escuchar "con desconfianza las interesantes conferencias de D. Juan Vilanova"2. Estos fraudes mostraban la fragilidad de la evidencia: los museos europeos habían comprado falsos cacharros mexicanos, joyería colombiana prehistórica hecha en París, ídolos hawaianos fabricados en China. Consumidos con cierta inocencia por los sabios, conducían a gastos inservibles, como el del museo de Berlín, que había gastado "I 3000 duros en cacharrería moabita de un par de años de antigüedad” (FALSOS..., 1888). La creación de nuevos tipos cerámicos y de nuevas culturas podía resultar del trabajo del arqueólogo pero también de las artes de un falsificador. La falsificación era un problema complejo y hacía dudar de la legitimidad de algunas disciplinas y saberes. En el marco del surgimiento y la consolidación de la prehistoria, Mortillet (I885, p. 525) recordaba que los móviles de las falsificaciones podían ser varios: el deseo de vender y hacer ganancia; el amor propio ligado al descubrimiento y publicación de algo notoriamente novedoso; el orgullo nacional o local vinculado a la posesión de algo notorio; los prejuicios religiosos y filosóficos; "la vendetta" contra alguien cuyo prestigio se quiere arruinar y, finalmente, el puro placer o amor por la mistificación. Peor lejos de ser algo que ocurre por fuera de la práctica de las ciencias, muchos arqueólogos participaron de las mismas. Pero en casi todos los países se repetía el fenómeno de Idar-Oberstein: el emporio de la falsificación se concentraba en algunas zonas y barrios, que reunían dinastías de artesanos. En México, desde el Siglo XVII hasta mediados del XIX las antigüedades mexicanas procedían de Tlatelolco, un barrio de la ciudad capital, especializado en alfarería negra, copia de la de los antiguos aztecas $^{3}$. Oaxaca era la fuente de ídolos zapotecas y el pueblo de San Sebastián de vasos teotihuacanos. A partir de 1830 se incorporaron falsificaciones en alabastro italiano y en huesos humanos tomados de los osarios de la ciudad, donde se grababan signos copiados de las piezas exhibidas en el Museo Nacional de México (BATRES, [19--?], p. 9). Muchos falsificadores entraron al mercado legal del turismo declarando que sus piezas eran falsas y vendiéndolas como manifiesta imitación. Batres relata el caso de los alfareros de San Sebastián de Teotihuacan,

quienes al realizar sus producciones, advierten al comprador que ellos la han hecho.Antiguamente estos mismos hicieron pasar por buenas las

2 Sobre Vilanova, ver Pelayo López e Gozalo Gutiérrez (2012).

3 Batres ([19--i], p. 24) destacaba que las falsificaciones se originaron por la demanda de jarros y figuras de barro usadas por los indianos y que los españoles remitían a sus amigos y familias. A raíz de ello, los conquistadores obligaron a los indios alfareros del barrio de Tlatelolco a que fabricasen ollas rodeadas de dioses, jarras con las asas de serpiente, esculturas humanas sentadas. Esas alfarerías estaban determinadas por la forma europea, "no teniendo de indio más que alguna que otra aplicación moldeada en originales". Según el mismo Batres, esta industria perduró en Tlatelolco hasta 1860, cuando empezó a desaparecer esta parcialidad india y a transformarse en un barrio de México habitado por mestizos y europeos. 
piezas de su fábrica pero los convencía de que hacían mal en engañar y que les tenía más en cuenta ofrecer sus piezas como una industria de la localidad (BATRES, [19--?], p. 14).

Esta información revela también la novedad del problema: en 1830 los coleccionistas europeos y estadounidenses señalaban que en México el fenómeno de la falsificación todavía no se había desarrollado (FRANCK, I83I).

Paradójicamente, los manuales sobre falsificaciones crearon una literatura que se reproducía y copiaba a sí misma, relatando los mismos casos y, en todo caso, sumando los nuevos o abundando en aquellos específicos de la zona de donde era oriundo el desmitificador (BATRES, [19--?], MUNRO, 1905, VAYSON DE PRADENNE, 1932). Los manuales retroalimentaban el circuito que iba de lo verdadero a lo falso y viceversa: al señalar los caracteres indiciarios de una falsificación y los métodos para descubrirla, daban también la receta para mejorarla. La química y la física al alcance de la policía y del burgués medio, incluía al falsificador. La pregunta acerca de cómo distinguir lo falso daba también la respuesta a cómo lograr falsificaciones cada vez más sofisticadas: las fórmulas químicas también servían como detalladas recetas. Si estas fueron usadas por los falsificadores, queda por probarse: los autores de los mismos descansaban demasiado en la certeza de moverse círculo que no se cruzaban. En efecto, todos comparten el tópico de la desconfianza hacia el obrero que se aprovecha de los descuidos del "profesor" (EUDEL, I884; SIEGFRIED, 1927; MUNRO, 1905; PODGORNY, 2013).A muchos falsificadores, los perseguía el estigma del alcohol y su origen proletario (BATRES, [19---?]; MUNRO, 1905). Sin embargo, la relación entre falsificadores y profesionales no se agotaba en los manuales: Batres ([19--?], p. 6) varias veces empleó a los artífices oaxaqueños que estafaban a los profesores de la Universidad de Columbia y del Museo de Historia Natural de Nueva York para ejecutar dibujos de las copias de monolitos. Munro (1905) también recuerda que el famoso "Flint Jack" dio clases y demostraciones de tallado del sílex a la usanza prehistórica ante varias sociedades de anticuarios británicos. Por el lado de los copistas, los dibujantes empleados por los arqueólogos profesionales aprovechaban el conocimiento y habilidades adquiridas en el manejo de los originales para lanzar al mercado un objeto producido por sus manos. Batres denunciaba, por ejemplo, al dibujante empleado para copiar las láminas de la obra histórica de Sahagún que en Europa daba golpes certeros con copias espurias de las mismas (BATRES, [19--?], p. 14). El problema era universal: franceses, ingleses y alemanes compartían la posibilidad de ser estafados por los obreros. Las exposiciones universales no solo promovían los modelos y las materias primas, paralelamente exhibían, en sus secciones científicas, series de piezas destinadas a poner en guardia a los aficionados y a los directores de museos. Entre las exposiciones que tomaron estas medidas se cuenta la de París de 1878, donde Ernest Hamy, conservador de la exposición Etnográfica del Trocadero y promotor del museo (DIAS, I99I), instaló armarios especiales piezas falsas para que el público las estudiara de cerca (BATRES, [19--?]; EUDEL, 1884). Los museos siguieron esta costumbre y, desde ciudad de México a Graz, conservaron y exhibieron las piezas "falsas" adquiridas o donadas como pudoroso testimonio del engaño y advertencia para los inexpertos.Asimismo, los datos de los manuales para alertar sobre el tráfico de falsificaciones se usaron en la literatura etnológica: Batres y Graebner recurrirían a la traducción de la segunda edición de Eudel, donde, a su vez, se habían recopilado los testimonios de los prehistoriadores y curadores de algunos de los museos franceses de la época. A pesar de las incontables falsificaciones, se concluía que en la etnografía como 
en la prehistoria las falsificaciones no eran de preocupar (cf. GRAEBNER, 1940; SIEGFRIED, 1927). En etnología, los centros principales de falsificación remitían a los dominios de la arqueología de las altas culturas asiáticas y americanas (GRAEBNER, 1940, p. I7), donde se podían obtener beneficios económicos.

A pesar de ello, en 1927, el Laboratorio Criminalista de la Dirección de Policía de Viena realizaba una encuesta entre prehistoriadotes, etnógrafos, geólogos y expertos en mineralogía, tecnólogos, físicos y químicos; las falsificaciones de objetos prehistóricos, aunque muy frecuentes, no habían merecido estudios por parte de los profesionales, a pesar de merecer más de una monografía criminalista. Sin embargo, la literatura criminalista carecía de trabajos teóricos o casuísticos sobre falsificaciones de objetos prehistóricos. Las encuestas arrojabas resultados contradictorios: los prehistoriadores y curadores de los museos vieneses confiaban en su experiencia de observación como garantía absoluta para impedir el engaño. Apelaban a la química y a las recetas dadas por Eudel y otros manuales ya aparecidos como el de Neuburger (1998). Pero en los laboratorios dudaban, aportando una mayor sutileza sobre la variabilidad humana que los humanistas: un análisis químico podía dar la composición de las cosas, pero no decir si eso representaba la composición verdadera: la referencia europea no siempre servía para juzgar objetos de otras épocas y lugares. Lo mismo ocurría con las pátinas: la descripción química no alcanzaba para juzgar su antigüedad.Así, los técnicos de los análisis químico o microscópico de la materia, relativizaban, en ciertos casos, la eficacia de estos métodos. Otra huella de la falsificación surgía de las huellas de fabricación: los rastros de cuchillos de acero, del papel de lija o de un molde galvanoplástico, llevaban al diagnóstico seguro. Por ello, los manuales insistían en la casuística, manteniendo los viejos hechos y sumando nuevos, algunos tan notorios como la tiara de Saïtapharnés (VAYSON DE PRADENNE, 1932), comprada por el Museo del Louvre, adjudicada luego a un falsificador ruso de Montmartre. Otro elemento empeoraba la capacidad de diagnóstico: las cosas antiguas aparecían de manera muy distinta a cómo se mostraban o guardaban en los museos. Cuando se hallaban, los objetos aparecía oxidados o en pedazos; su recomposición en los museos, poco se asemejaba a ese estado: era ¿verdadera o falsa? Quizás las similitudes entre civilizaciones distantes se deban más a los modelos de reconstrucción que a las piedras tapadas por la selva y los años (PODGORNY, 2007; 2008). Sumado a todo ello, existía aquello que Graebner llamaba "hipercrítica": considerar falsas a cosas luego declarados auténticas, como las pinturas rupestres del Cantábrico (cf. SIEGFRIED, 1927) y los bronces de Benin (GRAEBNER, 1940).

Los objetos de los pueblos primitivos del presente planteaban el límite entre objetos etnográficos y prehistóricos verdaderos o puros. Como destacaba el criminalista vienés, citando a Buschan "aquello que hace interesante los hallazgos prehistóricos de África desde un punto de vista etnográfico, consiste en la larga supervivencia de instrumentos de piedra aún en tiempos históricos tardíos”. Así se comentaba: “en Berlín hace poco se vieron Patagones que ante los ojos de los visitantes de una exposición tallaban de las astillas de botellas de vidrio y con instrumentos de hueso las más hermosas puntas de flechas" (SIEGFRIED, 1927, p. 33). Como en el caso de la industria de jade maorí-alemana, por más que estas fueran utilizadas por los maoríes, se las trataba como copia o, en el mejor de los casos, una intromisión en el núcleo de la cultura primitiva. Sahlins (2000, p. 159) ha afirmado que la antropología -o la etnología- puede considerarse la única disciplina fundada sobre el principio del búho de Minerva: sus inicios como disciplina profesional coinciden con la desaparición de su 
materia de estudio. Aunque los llamados "pueblos primitivos" no se estuvieran extinguiendo, sus "culturas", sin dudas, desaparecían (o "aculturaban") bajo la presión del orden capitalista mundial. En esa posición, la práctica de la etnología se acercaba a la arqueología prehistórica y los objetos etnológicos solo podían ser testimonios de estados pasados.

Parafraseando a Rheinberger (2003), el objeto etnológico de las primeras décadas del Siglo XX aparece como representación de sí mismo. La etnología transformaba a las cosas en testimonios directos a sabiendas que aún en los niveles microscópicos, no tenían un único significado. Graebner concedía:Toda falsificación es también un producto cultural, salvo que no procede del piso cultural (Kulturboden) o tiempo cultural (Kulturzeit), al cual pretende pertenecer ${ }^{4}$ En este sentido la pregunta sobre la autenticidad sería, en verdad, un requisito especial para la determinación de la historia cultural del objeto. Sin embargo, la obsesión por saber si las cosas debían ser vistas como objeto "verdadero" o auténtico sobreviviría en todo el siglo XX. En ello está en juego la dimensión fetichista de los objetos de la etnología (MAYER, 2002) y también la idea de un "mapa de la autenticidad" (GUMBRECHT, 1997, p. 267). En el siglo XX, la autenticidad significó la opción por la tradición y el pasado, mientras que el opuesto, la "artificialidad", aparece en dirección contraria con lo "auténtico". América del Norte (excluyendo a México) y algunas ciudades de Europa simbolizaron el mundo de lo artificial y la anticipación del futuro, mientras que lbero-América, la periferia geográfica de Europa y algunos puntos del continente africano se consolidan como los espacios donde sobrevivía la "autenticidad" (GUMBRECHT, 1997, p. 267), en una geografía que se superpone con distinciones binarias tales como "centro" y "periferia". Singularmente, las amenazas a la comodidad de estas oposiciones procede, precisamente, de los espacios paradigmáticos de la tradición y el pasado: los obreros y peones, rusos, españoles o ingleses, los comerciantes y los ilustradores mexicanos cruzan permanentemente estas fronteras, desafiando cualquier intento de una geografía simbólica basada en la creencia de un estado prístino de la cultura y la naturaleza. Los "falsificadores" cuestionan la ilusión de comunicarse directamente con el pasado.

A continuación nos referiremos a las cerámicas del Arroyo de Leyes, provincia de Santa Fe, Argentina, una historia donde se entremezclan geografías y personajes "marginales" y los conflictos entre distintos grupos por definir lo verdadero y lo falso en el marco de los museos argentinos.

\section{El arroyo Leyes}

En 1935, el director del Museo Antropológico y Etnográfico de la Facultad de Filosofía y Letras de la Universidad de Buenos Aires escribía:"en un lugar próximo a la ciudad de Santa $\mathrm{Fe}$, que las condiciones regionales mantuvieron aislado hasta hace poco -en el arroyo Leyes-, acaban de realizarse hallazgos arqueológicos que pueden considerarse como los más trascendentes verificados en el País en los últimos tiempos" (OUTES, 1935, p. 9). Siempre según Outes (1935, p. I0), el ambiente del Leyes conservaba por entonces: "el aspecto natural primitivo": los bosquecillos, el arbolado ribereño; los grandes embalses de 'irupés', la población que traicionaba su raigambre aborigen y los pequeños caseríos, conservaban "la fisonomía evocadora, lugareña y agreste, de los primeros años de su existencia.” El Leyes, en la periferia de la ciudad de Santa Fe, emergía para los arqueólogos como

4 "Toda falsificación no deja de ser el producto de una cultura; solo que no procede del medio cultural al cual pretende pertenecer" (GRAEBNER, 1940, p. 36). 
un contexto no contaminado, olvidado de la historia, refugio de la naturaleza original y las costumbres de épocas pasadas. La polémica por venir se plantearía alrededor de la "contaminación" de esa geografía al margen de la historia.

El 'paradero' arqueológico había sido descubierto en 1930 por el viajante Fernando R. Mántaras, de la ciudad de Santa Fe quien, en uno de sus viajes, detuvo el auto en una parte que se acercaba al agua, descendiendo hasta la orilla, donde notó la abundancia de restos de alfarería.Al no encontrar "ninguna pieza de valor", siguió viaje. Pero, a partir de entonces, se dedicó a buscar "más prolijamente". En una de esas ocasiones halló una media vasija de forma cónica y dimensiones reducidas, "pero con una perfección de líneas, uniformidad y poco espesor de pasta, etc. que le dan valor" . Este interés llamó la atención de un poblador de apellido Pérez, quien desde su rancho, veía a Mántaras juntando cosas. Cuando se enteró que buscaba vasijas, puso a sus disposición a toda la familia. Mántaras cambió su rutina, para empezar a detenerse en el rancho del Sr. Pérez, y llevarse un sinnúmero de cacharros. Esta cosecha duró varios meses y alcanzó la extensión de una hectárea. En carta a Joaquín Frenguelli ${ }^{6}$, director del Instituto del Museo de La Plata, Mántaras aclaraba: jamás había aparecido "no digo una vasija entera, ni siquiera una fracción o un trozo de un rostro humano como los que tanto abundan en los objetos que han vendido por ahi""

Mántaras, solo o en compañía de Amelia Larguía de Crouzeilles, también de la ciudad de Santa Fe, realizó excavaciones con el concurso de familiares. La Sra. de Crouzeilles, miembro de la sección local de la Sociedad Científica Argentina, informaría de sus investigaciones en agosto de 1934, reconociendo la deuda con Mántaras e informando de los hallazgos en el marco de los últimos descubrimientos en la zona de Santa Fe. En 193I, en una de sus excursiones, había encontrado ocasionalmente "la mitad de una pieza de pasta y decoración; dando lugar este hallazgo a búsquedas empeñosas con resultados ampliamente satisfactorios" (LARGUÍA DE CROUZEILLES, 1934). Como resultado de esta comunicación, el Museo Etnográfico yAntropológico de la Faculta de Filosofía y Letras de la Universidad de Buenos Aires envió una misión de estudio, integrada por Francisco de Aparicio, jefe de la sección Arqueología de dicha institución, el profesor de geografía Federico Daus -adscripto a la sección de Antropogeografía de dicho museo-y Joaquín Frenguelli, del Museo de La Plata, linstituciones que estaban a cargo del cuidado de la Ley Nacional 9080 de ruinas y yacimientos arqueológicos y paleontológicos. La comunicación tuvo otras repercusiones: los entonces muy populares hermanos Wagner de Santiago del Estero, comparaban algunos de los hallazgos del Leyes con cerámicas de Hissarlik y de la Civilización Chaco-Santiagueña (cf. PODGORNY, 2004;WAGNER et al., 1934). Para Larguía de Crouzeilles (1936) la tipología del Leyes evidenciaba el contacto con otras civilizaciones y, citando al Director del Museo Nacional de Lima, proclamaba: "Cada pueblo, cada época, cada cultura, ha producido su propia obra inconfundible, peculiarísima. Un tipo le corresponde. Seriándolos, se observa su evolución y las ajenas influencias, así como se fija su módulo. Hay por lo tanto una tipología que sirve a los mismos fines de una determinación cronológica".

Pero antes, en octubre de 1933, al Leyes había llegado el agente de seguros Manuel A. Bousquet, a la sazón residente en Santa Fe, que emprendió una serie

5 Mántaras [carta], 1936 ago. 31, Santa Fe [para] Frenguelli [manuscrito].

6 Joaquín Frenguelli, médico graduado en la Universidad de Roma, había nacido en esa ciudad en I883. En la Argentina actuó desde 1920 como profesor de Geología y Paleontología en la Facultad de Ciencias de la Educación de la Universidad del Litoral (Santa Fe). especializado en invertebrados y paleobotánica, fue desde 1934, secretario, luego director, del Instituto del Museo de la Universidad de La Plata.

7 Mántaras [carta], 1936 ago. 3I, Santa Fe [para] Frenguelli [manuscrito]. 
de recolecciones con activa participación de otro poblador del terraplén del Leyes. Con la intervención de este último, ubicado en el rancho de un pescador criollo de apellido Quiroga, "de nacionalidad extranjera", empezaron a comparecer vasijas y cacharros enteros, y un sinnúmero de representaciones plásticas antropomorfas, zoomorfas y fitomorfas, que el poblador vendía a buen precio. Bousquet presentaba su yacimiento como un paraje de gran extensión, situado en la propiedad del señor Manuel Irigoyen, quien, contrariamente a lo que les sucedería a los viajeros de los museos platense y porteño, apoyaba las exploraciones del agente de seguros ${ }^{8}$. Bousquet, uno de los ocho socios adherentes de la Sociedad Argentina de Antropología desde su fundación en 1936, era presentado como "un arqueólogo silencioso, un estudioso de la arqueología argentina que ha rehuido siempre -podríamos decir sistemáticamente-, el brillo a veces falso, que dan los círculos científicos" (VIGLIANI, 1938). Bousquet atesoraba, en su casa de la ciudad de Santa Fe (FURLONG, 1935) y luego en su casa del barrio de Palermo, en Buenos Aires, "un verdadero museo de cosas nuestras" (piezas arqueológicas, armas y documentos de los próceres del panteón nacional). "Adorador de la Patria, cultor de los elementos útiles para el estudio de su desarrollo como pueblo culto", realizó excavaciones y estudios en los territorios del sur, La Pampa, Córdoba y Santa Fe. Bousquet, como todos, se apropiaba de los hallazgos de pescadores y pobladores locales, pretendiendo haber descubierto y excavado el "cementerio" de donde extrajo "más de dos mil piezas enteras y muchos cajones de fragmentos, compuestos de gran variedad de asas y fragmentos grabados" (VIGLIANI, 1938; BOUSQUET, 1936) 9 . Las colecciones privadas como las de Bousquet abundaban en la Argentina. Precisamente en 1930 el Museo Antropológico y Etnográfico había adoptado una política de reconocimiento y publicidad de las colecciones particulares para su uso como material científico. En ese marco debe entenderse la difusión de la Colección Breyer de antigüedades del noroeste argentino ${ }^{10}$ (APARICIO, 1930-1931) y de la misma colección Bousquet, a través de una exposición sobre el arte de los aborígenes de Santa Fe, cuyo catálogo era prologado por Félix Outes, director del museo etnográfico de Buenos Aires (Amigos del Arte 1935). Aparentemente, Bousquet se enteró de la ubicación de los hallazgos de Mántaras e hizo un viaje de ex profeso, poniéndose al habla con Pérez al que le adquirió lo reservado para el viajante,

ofreciéndole en adelante, pagar tan bien que más le convenía dejar de sembrar y sus otros quehaceres y dedicarse a buscar 'cacharros' según

8 Aparicio (1937, p. 8) diría en "Los Zapallos el campo donde se han efectuado últimamente numerosos hallazgos, se encuentra en su casi totalidad cultivado, y sus pobladores prohíben todo trabajo de excavación". Para obtener la colaboración de los mismos en 1936 hubo de invitar a Bousquet (APARICIO, 1937, p. I2).

9 En carta a Martín Doello Jurado, director del Museo Argentino de Ciencias Naturales, afirmaba: "Conocidos son al Sr. Director, los antecedentes de este yacimiento descubierto por mí, y que a (sic) sido considerado, como uno de los más valiosos hallazgos efectuados en los últimos años" (Bousquet [carta], 1937 oct. 29, Buenos Aires [para] Martín Doello Jurado).

10 Aparicio (1930-193I, p. 349-50) comentaba: "El número y calidad de las colecciones particulares de gran valor científico o artístico que existen en Buenos Aires, es muy superior a lo que el público en general puede suponer. Parte de esas colecciones han sido reunidas, obedeciendo a impulsos subalternos de notoriedad o snobismo, por simples acaudalados que procuran dar interés a su persona o a su residencia rodeándose de buena copia de objetos exóticos o de reconocido valor intrínseco. Otras, en cambio, so la obra de espíritus selectos que, a los medios adquisitivos materiales, unen condiciones de cultura y de inteligencia que les permiten reunir y sistematizar colecciones, sino con la preparación de un especialista, al menos con la competencia de un aficionado erudito y capaz. Esta serie constituye un riquísimo acervo de material científico, ignorado -por estar en manos de particulares- no sólo del público sino aún de los estudiosos y especialistas para quienes resulta un venero inutilizable. Ordinariamente las colecciones privadas no reportan ningún beneficio para la investigación científica, más por la ignorancia de su existencia que por egoísmo de sus propietarios." 
propia manifestación de Pérez. Recalco esto porque fue el comienzo de la comercialización que por desgracia se generalizó e hizo dudar sobre la autenticidad de todas las piezas de ese paradero (MÁNTARAS, 1936).

En mayo de 1936, se presentó el "vendedor" que vivía en el rancho de Quiroga, ofreciendo varias piezas que guardaba para Bousquet, pero que en vista de su tardanza, necesitando dinero, resolvió ofrecerlas a la Sra. de Crouzeilles y a un Padre Profesor de Historia en el Colegio de la Inmaculada Concepción de Santa Fe. Se le adquirieron varias piezas enteras, entre las cuales figuran tres donde

fácilmente se ha individualizado el objeto con que han sido hechas las impresiones que forman el dibujo que las adornan (tapa de hojalata de bordes ondeados, objeto de hierro en forma de cuña y una moneda o pieza circular que lleva un número dos de imprenta en su centro (MÁNTARAS, 1936).

De tal manera, en el Museo de La Plata estaban convencidos que "el Señor Bousquet, en el deseo de acrecentar sus colecciones con piezas extraordinarias, había casi monopolizado la adquisición de los materiales ofrecidos en venta", sugiriendo también que con ello, habría fomentado la falsificación (FRENGUELLI, 1937, p. 62-63), con tal tono que se lo acusa de abogado de otro coleccionista.

Efectivamente, Antonio Serrano" en Paraná, se manifestaba a favor de Bousquet (SERRANO, 1934), quien le encomendó el estudio de su colección, donde reconoció tres manifestaciones culturales distintas, una típicamente guaraní; otra con representaciones plásticas de psitácidos (loros); y una tercera, - la que generaba dudas y polémicas- muy reciente, atribuida a las tribus chaqueñas reducidas durante el siglo XIX en las inmediaciones de Santa Fe. En esta, la fauna representada consistía en vacunos y caballos. Aparecía también un disco de barro -sol o escarapela- que Serrano emparentaba con la liturgia cristiana y una posible representación de la eucaristía. Desechaba la posibilidad de falsificación e insistía en la manufactura indígenas. Serrano recalcaba: el arte y los objetos no eras "chaqueños" en sentido estricto, de este carácter solo quedarían las ideas plasmadas en los objetos. La polémica, a partir de ese momento, se centró en dos personajes: Serrano y Frenguelli.

Frenguelli hizo tres visitas al yacimiento del Leyes: una vez solo, otra, con Larguía y la última entre el 28 de agosto y el 8 de septiembre de $1934^{12}$, la ya citada con de Aparicio ${ }^{13}$, cuando tuvo a su cargo las observaciones geológicas y geográficas. También inspeccionó la colección Bousquet, considerando que entre centenares de piezas, al lado de materiales realmente valiosos, observaba objetos groseramente falsificados. El 31 de marzo de 1935 Frenguelli denuncia en el periódico El Litoral de Santa Fe "las falsificaciones del Leyes" como "intromisión de incompetentes y especuladores en los dominios de los problemas arqueológicos americanos". Bousquet, inmediatamente, empezó a tejer alianzas: en abril regalaba dos piezas al sacerdote jesuita Miguel Ramognino, quien a su vez las donaba al "Museo de Antigüedades" del Colegio del Salvador de Buenos Aires (FURLONG,

II Antonio Serrano (Paraná, I899), era profesor de enseñanza secundaria graduado en la Escuela Normal de Paraná. Profesor suplente de Arqueología Americana de la Universidad del Litoral, y titular de la misma materia en la Escuela de Paraná. Dirigió el Museo de Entre Ríos desde su establecimiento en 1924.

12 “Al Sr. Presidente de la UNLP, en ejercicio de la Dirección del Instituto del Museo, Dr. Ricardo Levene", Informe de Campaña de Frenguelli, AHMLP, Carpeta 17, expediente F 179.

13 Aparicio (Buenos Aires, 1892) actuó como profesor de Introducción a los Estudios Históricos y de Arqueología Americana en la Facultad de Ciencias de la Educación de la Universidad Nacional del Litoral y más tarde en la Facultad de Filosofía y Letras de la Universidad de Buenos Aires. En esos años se desempeñaba como jefe de la sección arqueológica del Museo Etnográfico. 
1935). Guillermo Furlong ${ }^{14}$, partidario de la unidad cultural de las piezas de la colección Bousquet, las asignaba a "manifestaciones de la cultura mocobi" de mediados del siglo XVIII, apoyándose en "la poca profundidad de los yacimientos, la escasa pátina y, sobre todo, los objetos mismos y sus manifestaciones” (FURLONG, 1935, p. 20). Asimismo recurría a un manuscrito del sacerdote jesuita Florián Paucke o Baucke, donde se relataba e ilustraba la afición a la elaboración de la cerámica de los indígenas reducidos en San Javier. Este documento, según Furlong, alejaba "sino es que deshecha enteramente, la posibilidad de una falsificación moderna, como alguien ha supuesto. Con satisfacción, y sin temores, puede el Colegio del Salvador exhibir en las vitrinas de su Museo de Antigüedades las preciosas piezas de alfarería mocobí con que, gracias al Sr. Bousquet, acaba de ser honrado" (FURLONG, 1935, p. 2I). En 1937 Bousquet entregó piezas en depósito al Museo Argentino de Ciencias Naturales de Buenos Aires y vendió una veintena de piezas de su colección al Ministerio de Justicia e Instrucción Pública de la Nación con destino al Museo Antropológico y Etnográfico de la Facultad de Filosofía y Letras de la Universidad de Buenos Aires ${ }^{15}$.

Contrariamente a Serrano y Furlong, Frenguelli insistiría en el aislamiento del Leyes y que las piezas "verdaderamente" indígenas estaban desconectadas de todo intercambio histórico. Sin indicios materiales de la cultura europea, concluía "allí la vida indígena se desarrolló completamente al margen de la extranjera y con absoluta independencia de ella" ${ }^{6}$. Las piezas enteras y raras se adjudicaban a las manos e intereses lucrativos de "algunos pobladores extranjeros, que viven en ranchos próximos al puente sobre el arroyo Leyes"|7. Según Frenguelli las piezas "no respondían a la técnica ni a la ideología de los alfareros indígenas ni de estas regiones ni otras regiones conocidas de América". Los objetos diferían de "los auténticos" por su cocción, el carácter de la pasta y la naturaleza de sus grabados. Se trataba de "composiciones incompatibles con la sobriedad y la elegancia de las ornamentaciones indígenas", que los falsificadores habían variado con demasiada exuberancia,"no reparando que en el acervo indígena local, ellas están reducidas a pocos sujetos. La fantasía de los falsificadores no ha tenido límites, llegando a un colmo bastante grotesco" (FRENGUELLI, 1937, p. 65). Contrariamente a la actitud que se fomentaba desde los museos de Buenos Aires, rompía lanzas, recurriendo a un tópico muy abundante en la segunda mitad del Siglo $X X$ : la relación directa entre coleccionismo privado y la corrupción de los pobladores locales, causa principal de la destrucción de la evidencia procedente del pasado:"Para desgracia para la ciencia pura, la avidez de los coleccionistas desconocedores de la arqueología o guiados por fines subalternos, ha despertado en los lugareños la industria de los seudocacharros, que constituye para ellos un verdadero 'modus vivendi' y que ocultan diligentemente. En nuestros días, puede cualquiera obtener todos los seudocacharros que desee, con tal que los pague ${ }^{18 "}$ (FRENGUELLI, 1937, p. 69).

I4 El sacerdote jesuita y doctor en Filosofía Guillermo Furlong Cardiff (Santa Fe, 1889) se graduó en Georgetown (Washington) y el Colegio Máximo de Sarria de Barcelona (1914), actuaba como profesor de inglés en el Colegio del Salvador de Buenos Aires. Se había especializado en historia colonial, bibliografía rioplatense y cartografía histórica.

I 5 Bousquet (1937). Más tarde se incorporarían algunas piezas al Museo de Córdoba.Varios objetos de la llamada Colección Bousquet de Córdoba fueron ingresados el 18 de junio de 1945. Proceden de Arroyo de Leyes, provincia de Santa Fe. La ficha de inventario de cada pieza tiene un precio asignado que va desde 20, 50, 150 a 200 pesos. Debo estos datos a la generosidad de Mirta Bonnin.

16 "Al Sr. Presidente de la UNLP, en ejercicio de la Dirección del Instituto del Museo, Dr. Ricardo Levene", Informe de Campaña de Frenguelli, AHMLP, Carpeta I7, expediente F 179.

17 “Al Sr. Presidente de la UNLP, en ejercicio de la Dirección del Instituto del Museo, Dr. Ricardo Levene”, Informe de Campaña de Frenguelli,AHMLP, Carpeta I7, expediente F 179.

18 Aparicio (1937, p. 12, nota I) destacaría que la costa del Leyes en 1936 estaba totalmente removida, presentando "el aspecto de los campos que han soportado un intenso bombardeo, efecto que, por fortuna, 
Frenguelli contrastaba la pureza de la autenticidad con la inconsistencia surgida de la intromisión de comerciantes, coleccionistas y "extranjeros": los indios locales, arrasados de la región alrededor de 1650, se caracterizaban por condiciones de vida primitiva, indemnes de influencias hispánicas, "tal como se deducen del contenido arqueológico auténtico de los paraderos del Leyes". De alguna manera, aquello que se presentaba con "mezclas" de otras sociedades solo podía deberse a la mala fe de quienes quisieran lucrar con lo seudo real. Frenguelli se aprovechaba de algunos indicios para cuestionar todo el conjunto, refiriéndose a una vasija denunciaba: "cada impresión lleva en el centro un pequeño número 2 , de dos milímetros de lado, invertido, en relieve y de contornos bastante nítidos y bien marcados", hechos con un dedal de coser número 2. Otras decoraciones igual de sospechosas estaban hechas con tapitas metálicas "made in England”, características de las botellas de agua mineral de marca Villavicencio.

Aparicio, por su parte, publicaría un informe en 1937, donde resumía las exploraciones realizadas bajo los auspicios del Museo Antropológico de Buenos Aires en 1935 y 1936. Allí repetía -pero con un tono moderado- el supuesto carácter de superchería de algunas piezas, pero recalcaba que la colección Bousquet generaba un efecto "desconcertante", ya que algunos objetos abrían un interrogante "que aún no tiene respuesta satisfactoria". Estas cerámicas eran un hecho nuevo en "nuestras investigaciones arqueológicas" (APARICIO, 1937, p. 8). En su informe, de Aparicio insistía en los cuidados tomados para constatar las condiciones del hallazgo para protegerse de las versiones de engaño que circulaban sobre el paradero, no quedándole otra opción que admitir que los mismos estaban in situ. Esta cerámica -llamada "tipo Leyes"- se describía en los siguientes términos: grotesca, deforme, reveladora de un espíritu mezquino que llega a ser repelente (APARICIO, I937, p. II, nota I). Se la comparaba con la cerámica del Paraná “de tipo corriente", excelente, de superior factura, valor artístico y cocción y de alto mérito escultórico, en parangón con la del Leyes. La obsesión con la autenticidad de las culturas indígenas, llevaba a la descalificación de los objetos resultantes de la historia, de la mezcla y la "aculturación". Mientras Frenguelli los descartaba, adjudicándolo a interferencias comerciales y extranjeras, Aparicio los aceptaba como objetos etnológicos, sin ocultar que le provocaban cierto rechazo.

A pesar de esta trayectoria de "aceptación conflictiva", como objeto científico las cerámicas y la cultura del Leyes tuvieron una vida muy corta: en la década de 1940 desaparecen de la arqueología y se refugian en las colecciones de los museos. Recién en 1980 Alberto Rex González le dedicaría dos páginas de su monumental obra: las primeras luego de cuarenta años. Allí arriesgaba la idea que ahora cobra vigor: estas cerámicas, desacreditadas por las denuncias de Frenguelli, podrían ser, en parte "la obra de indígenas post-hispánicos, entre los que no habrían faltado grupos de africanos mezclados con aquellos" (GONZÁLEZ, I980, p. 427). González (1980, p. 426) hablaba de un problema "difícil y complejo, planteado hace años y aún no resuelto definitivamente, pero de indudable interés arqueológico y estético". En el siglo XXI, las cerámicas del Leyes están reingresando al dominio científico como objetos de esclavos o libertos negros radicados en la zona de Colastiné (CERUTI, 2004, SCHAVELZON, 2003).

sólo conocemos a través del cinematógrafo". Asimismo volvía a recordar que los pobladores del lugar habían hecho de la búsqueda de material arqueológico su principal actividad.Aprovechaban la consistencia arenosa del terreno para cavar pozos más o menos circulares de un medio metro de profundidad y luego, con una vara de acero, sondeaban en todas direcciones. 
Mora (1988, p. 346) ha recordado:

Una falsificación, sea del tipo que sea, casi nunca es producto exclusivo de la imaginación de su autor, sino que se basa en documentos reales o ficticios ya existentes, sea para ratificarlos, para complementarlos o, simplemente, para conferirles mayor autoridad.

La historia del Leyes nos muestra que la falsificación podría adjudicarse a Bousquet, a los extranjeros del Leyes pero también por la hipercrítica de Frenguelli. No dispuestos a admitir lo extraño, estos objetos, al compararlos con "lo real" y "lo auténtico", no podían ser otra cosa que una ficción fraudulenta de un elemento extraño a esa historia y paisaje prístinos, detenidos en el siglo XVII. Todavía está por verse si las cerámicas del Arroyo Leyes renacerán para la ciencia en una geografía liberada de la periferia y de la autenticidad. Las colecciones de los museos serán cruciales para ello.

Agradecimientos: Este trabajo forma parte del PIP 0I 16. Otras versiones fueron consideradas en el Congreso de Filosofía e historia de la Ciencia, Universidad de La Laguna (2005) y el I Simpósio de Filosofia da Ciencia, CEADS-UERJ, Ilha Grande (2006).Agradezco la ayuda y comentarios de Susana García, Máximo Farro, Carlos Ceruti,Andrea Pegoraro y de los bibliotecarios del Museo Etnográfico (UBA), Museo de La Plata y Museo de Ciencias Naturales Bernardino Rivadavia (AMCN).

\section{Referencias}

AMIGOS DELARTE. El arte de los aborígenes de Santa Fe. Buenos Aires: [s.n.], 1935. APARICIO, Francisco de. Colecciones particulares: la colección Adolfo Breyer. Solar, v. I, p. 349-355, 1930-1931.

APARICIO, Francisco de. Colecciones privadas: la colección Adolfo Breyer. Solar, v. I, p. 349-355, I 931.

APARICIO, Francisco de. El Paraná y sus tributarios. Historia de la Nación Argentina, v. I, p. 473-506, 1936.

APARICIO, Francisco de. Excavaciones en los paraderos del arroyo de leyes. Relaciones de la Sociedad Argentina de Antropología, v. I, n. 7, 1937.

BATRES, Leopoldo.Antigüedades mejicanas falsificadas: falsificación y falsificadores. México, D.F.: Soria, [19--?].

BOUSQUET [carta], 1937 oct. 29, Buenos Aires [para] Martín Doello Jurado.

BOUSQUET, Manuel. Habla para “EI Pueblo”. El Pueblo, 29 jul. 1936.

BOUSQUET, Manuel. Investigaciones arqueológicas en el arroyo Leyes, Santa Fe. Revista Geográfica Americana, v. 8, p. 16I-174, 1937.

CERUTI, Carlos. Aporte al conocimiento de la 'Cultura del Leyes': la colección del museo de Ciencias Naturales y Antropológicas 'Prof.Antonio Serrano', Paraná, Entre Ríos, Argentina. In: CONGRESO DE ARQUEOLOGÍA ARGENTINA, I5., 2004,Argentina.Actas... Río Cuarto: [s.n.], 2004.

DIAS, Nélia. Le musee d'ethnographie du Trocadéro (1878-1908): anthropologie et museologie en France. París: CNRS, 1991.

EDGE-PARTINGTON, J. Maori forgeries. Man, v. I0, p. 54-55, 1910.

EDGE-PARTINGTON, J. Maori forgeries. Man, v. 9, p. 56, 1909.

EUDEL, Paul. La falsificación de antigüedades y objetos de arte: alteraciones, fraudes y adulteraciones descubiertas. Buenos Aires: Centurión, 1947.

EUDEL, Paul. Le truquage: alterations, fraudes: contrefaçons dévoilées. París: Molière, 1884. 
FALSOS arqueólogos: el budhismo en París. La Capital, 28 sept. 1888.

FRANCK, Maximilien. Extraits de la lettre de M. Frank, sur sa collection d'antiquités mexicaines, et note de $M$. Jomard. Bulletin de la Société de Géographie, v. 15, n. 93-98, p. 283-288, 1831.

FRENGUELLI, Joaquín. Falsificaciones de alfarerías indígenas en Arroyo Leyes (Santa Fe). Notas del Museo de La Plata, v. 2, n. 5, 1937.

FURLONG, Guillermo.Alfarería Mocobí. El Salvador, v. I0, n. 104, p. 20-21, abr. 1935. GONZÁLEZ, Alberto Rex. Arte precolombino de la Argentina: introducción a su historia cultural. Buenos Aires: Filmediciones Valero, 1980.

GRAEBNER, Fritz Metodología etnológica. Prólogo de Fernando Márquez Miranda. Traducción de Salvador Canals Frau. La Plata: Universidad Nacional de La Plata, 1940. GRAEBNER, Fritz. Metodología etnológica. La Plata:Universidad de La Plata, 1940. GUMBRECHT, Hans Ulrich. In 1926: living at the edge of time. Cambridge: Harvard University Press, 1997.

LARGUÍA DE CROUZEILLES, Amelia. Algunos datos arqueológicos sobre paraderos indígenas en la Provincia de Santa Fe. Anales de la Sociedad Científica Argentina, v. II8, p. 216-221, 1934.

LARGUÍA DE CROUZEILLES, Amelia. Correlaciones entre la alfarería indígena encontrada en la región de Santa Fe y la de la provincia de Santiago del Estero. Anales de la Sociedad Científica Argentina, v. I28, p. 196, 1939.

LARGUÍA DE CROUZEILLES,Amelia. Datos arqueológicos sobre paraderos indígenas de Santa Fe.Anales de la Sociedad Científica Argentina, v. I22, p. 326-334, 1936.

LEHMANN-NITSCHE, Robert. Gefälschte ethnologische gegenstände in Buenos Aires. Sonder-Abdruck aus der Sonntags-Zeitung, Argentinisches Familienund Unterhaltungsblatt, n. I8, p. 2, 1905.

MÁNTARAS [carta], 1936 ago. 31 , Santa Fe [para] Frenguelli [manuscrito].

MAYER, Andreas. Mikroskopie der psyche: die Anfänge der Psychoanalyse im Hypnose-Labor. Wallstein: Göttingen, 2002.

MENDAZ, Fritz. El mundo de los falsificadores. Buenos Aires: Peuser, 1959.

MORA, Gloria.Trigueros y hübner: algunas notas sobre el concepto de falsificación.Archivo Español de Arqueología, v. 6I, n. I57-8, p. 344-8, 1988.

MORTILLET, Gabriel de. Faux paléoethnologiques. L'Homme, p. 525, sept. 1885. MUNRO, Robert. Archaeology and false antiquities. Londres: Methuen, 1905.

NEUBURGER, Albert. Echt oder Fälschung? Die Beurteilung und Behandlung von Kunstgegenständen. Augsburgo:Weltbild, 1998. (Reimpresión de 1924).

OLDMAN, W. Polynesian forgeries. Man, v. I0, p. I88, 1910.

ORVELL, Miles. The real thing: imitation and authenticity in american culture, 1880-1940. Chapel Hill: University of North Carolina Press, 1989.

OUTES, Félix. El arte de los aborígenes de Santa Fe. Buenos Aires:Amigos del Arte, 1935.

PELAYO LÓPEZ, Francisco; GOZALO GUTIÉRREZ, Rodolfo. Juan Vilanova y Piera (I82I-I893), la obra de un naturalista y prehistoriador valenciano: la donación Masiá Vilanova en el Museo de Prehistoria deValencia. [Valencia]: Diputación de Valencia, 2012. (Trabajos varios del servicio de investigación prehistórica del Museo de Prehistoria de Valencia, I I4)

PELAYO, Francisco; GOZALO GUTIÉRREZ, Rodolfo. Juan Vilanova y Piera (I82 II893), la obra de un naturalista y prehistoriador valenciano.Valencia: Servicio de 
Investigación Prehistórica del Museo de Prehistoria de Valencia II4, 2012.

PODGORNY, I. La prueba asesinada: el trabajo de campo y los métodos de registro en la arqueología de los inicios del Siglo XX. In: GORBACH, Frida; LÓPEZ BELTRÁN, Carlos (Ed.). Saberes locales. [S.I.]: El Colegio de Michoacán, 2008. p. 169-205.

PODGORNY, Irina. Medien der archäologie. Archiv für Mediengeschichte, v. 3, p. I67-79, 2003.

PODGORNY, Irina. The reliability of the ruins. Journal of Spanish Cultural Studies, v. 8, n. 2, 2007, p. 213-233.

PODGORNY, Irina. Tocar para creer: la arqueología en la Argentina, I910-1940. Anales del Museo de América, v. I2, p. 147-182, 2004.

PODGORNY, Irina. Falsehood on the move: the aztec children and science in the second half of the 19th century. Medicina Nei Secoli:Arte e Scienza, v. 25, n. I, p. I95-20I6, 2013.

RHEINBERGER, Hans Jörg. Präparate - 'Bilder' ihrer selbst. Eine bildtheoretische Glosse. [S.I.]:Akademie Verlag, 2003. p. 9-19. (Bildwelten des Wissens. Kunsthistorisches Jahrbuch für Bildkritik, I, 2. Oberflächen der Theorie).

RICHARD,Andree. Die nephritenindustrie in oberstein-idar. Zeitschrift für Ethnologie, v. 29, n. 6, p. 943-945, 1907.

SAHLINS, Marshall. Sentimental pessimism and ethnographic experience, or, why culture is not a disappearing 'object'. In: DASTON, L. (Ed.). Biographies of scientific objects. Chicago:The University of Chicago Press, 2000. p. I58-202.

SCHÁVELZON, Daniel. Buenos Aires negra: arqueología histórica de una ciudad silenciada. Buenos Aires: Emecé, 2003. p. 53-6I.

SERRANO,Antonio.Arqueología del Arroyo Leyes (Pro. de Santa Fe): noticia preliminar a propósito de la colección Bousquet. Memorias del Museo de Paraná, v. 8, 1934.

SHAPIN, Steven; SCHAFFER, Simon. Leviathan and the air-pump: hobbes, boyle, and the experimental life. [S.I.]: Princeton University Press, 1985.

SIEGFRIED, Türkel. Prähistorische fälschungen: eine rundfrage. Wissenschaftliche Veröfftlinchungen des kriminalistischen Laboratoriums der Polizeidirektion Wien, Graz, 1927.

SOUBERAIN, Léon. Nouveau dictionnaire des falsifications et alterations des aliments, des medicaments et de quelques produits employes dans les arts, l'industrie et l'economie domestique. Paris: Baillière, I874.

VAYSON DE PRADENNE, A. Les fraudes en archéologie préhistorique avec quelques exemples de comparaison en archéologie générale et sciences naturelles. Paris: Nourry, 1932.

VIGLIANI, Raúl. Un arqueólogo silencioso: una visita a la casa de Manuel A. Bousquet: su museo: sus colecciones: sus piezas arqueológicas. Caras y Caretas, p. 38-40, 1938.

VILLEGAS, Florencio. Breve contribución al estudio de la arqueología de la provincia de Santa Fe. Boletín del Colegio Nacional Manuel Belgrano, v. 5, n. 9, p. I47-I 54, I 934. WAGNER, Emilio Roger et al. La civilización Chaco- Santiagueña y sus correlaciones con las del viejo y nuevo mundo. Buenos Aires: Compañía Impresora Argentina, 1934. 